\author{
Cadernos de \\ ESTUDOS LINGḯlíTIICOS - (55.1), Campinas, Jan./Jun. 2013
}

\title{
A LINGUÍSTICA COGNITIVA ENCONTRA A LINGUÍSTICA COMPUTACIONAL: NOTÍCIAS DO PROJETO FRAMENET BRASIL ${ }^{1}$
}

\author{
MARIA MARGARIDA MARTINS SALOMÃO² \\ TIAGO TIMPONI TORRENT ${ }^{3}$ \\ THAIS FERNANDES SAMPAIO 4
}

\begin{abstract}
RESUMO
Neste artigo apresentaremos notícias sobre a construção que estamos empreendendo de recurso lexical para o Português do Brasil, http://www.framenetbr.ufjf.br, baseado na semântica de frames e vinculado à FrameNet de Berkeley, http://framenet.icsi.berkeley.edu, projeto cuja implementação alcança presentemente nove línguas. Para tanto, introduziremos brevemente o projeto teórico da semântica de frames, o projeto FrameNet como originalmente concebido e os dois principais desdobramentos em que hoje consiste a FrameNet Brasil: a saber, o dicionário eletrônico trilíngue COPA 2014 e o projeto Frames e Construções. Além de oferecer uma descrição parcial do Léxico do Português (tematicamente focado nos campos da COPA DO MUNDO e do TURISMO), o projeto ensaia também a proposição de um Constructicon, inicialmente constituído pela família das Construções de Finalidade e de Quantidade Indefinida.
\end{abstract}

PALAVRAS-CHAVE: FrameNet Brasil; Léxico; Construções.

\begin{abstract}
In this paper we will report the proceedings for building a new lexical resource for the Portuguese of Brazil, http://www. framenetbr.ufjf.br, based on semantic frames and connected to the Berkeley FrameNet, http://framenet.icsi.berkeley.edu, project, at this point, implemented for nine languages in the world. To this end, we will introduce briefly the theoretical design of frame semantics, the FrameNet project as originally conceived and the two major developments of the Brazil FrameNet project: namely, the 2014 WORLD CUP, a tri-lingual electronic dictionary, and our attempt to build a Constructicon for Brazilian Portuguese, the subproject Frames and Constructions. In addition to offering a partial description of the lexicon of Portuguese (thematically focused on the fields of the World Cup and Tourism), the project also describes the family of General-Purpose Constructions and Indefinite Quantity Constructions.
\end{abstract}

KEYWORDS: FrameNet Brazil; FrameNet Lexicon; Constructions.

\footnotetext{
${ }^{1}$ Este projeto conta com apoio financeiro da CAPES, CNPq e FAPEMIG.

2. UFJF, Juiz de Fora (MG), Brasil. mm.salomao@uol.com.br

3. UFJF, Juiz de Fora (MG), Brasil. tiago.torrent@ufjf.edu.br

4. UFJF, Juiz de Fora (MG), Brasil. thais.fernandes@ufjf.edu.br
} 
SALOMÃO, TORRENTI e SAMPAIO - A linguística cognitiva encontra a linguística...

\section{INTRODUÇÃO}

Um dos movimentos mais interessantes dos estudos da linguagem no final do século XX foi a capitalização dos avanços da linguística em direção a fronteiras interdisciplinares. Este movimento, inconteste no campo da linguística teórica, levou a diálogos frutíferos com as neurociências e com a biologia evolucionária, a um aprofundamento da agenda comum com a antropologia e com a psicologia cognitiva e a valentes esforços de modelagem computacional da gramática.

No campo dos desenvolvimentos tecnológicos, avultam as repercussões da linguística no campo educacional, a evolução da linguística clínica e, de nosso particular interesse, a construção de recursos lexicais e de dicionários eletrônicos dedicados a usuários humanos ou à legibilidade por máquina, que servem hoje (e podem servir muito mais) como condições de implantação mundial da web semântica.

Neste artigo apresentaremos notícias sobre a construção que estamos empreendendo de recurso lexical para o Português do Brasil, http://www. framenetbr.ufjf.br, baseado na semântica de frames e vinculado à FrameNet de Berkeley, http://framenet.icsi.berkeley.edu, projeto cuja implementação alcança presentemente nove línguas.

Para tanto, introduziremos brevemente o projeto teórico da semântica de frames, o projeto FrameNet como originalmente concebido e os dois principais desdobramentos em que hoje consiste a FrameNet Brasil: a saber, o dicionário eletrônico trilíngue COPA 2014 e o projeto Frames e Construções.

\section{A SEMÂNTICA DE FRAMES COMO PRINCIPAL HIPÓTESE DA LINGUÍSTICA COGNITIVA NO CAMPO DOS ESTUDOS DA SIGNIFICAÇÃO}

A semântica de frames é uma das expressões mais importantes do movimento nos estudos da linguagem, conhecido como Linguística Cognitiva (LC). Originária das "guerras linguísticas" que sacudiram o Modelo Padrão da Gramática Gerativa Transformacional nos fins dos anos sessenta e inícios da década de setenta do século passado, a Linguística Cognitiva, já na sua primeira versão, pode ser considerada uma das vertentes do grande paradigma funcionalista, já que também se insurge contra a "autonomia (formal) da linguagem" e a favor do papel da pragmática na explicação da gramática. Basta lembrar que um dos textos mais prestigiosos desta "onda inicial" são as conferências de Fillmore sobre o fenômeno da dêixis, proferidas em 1975 na Universidade de Santa Cruz, na California.

No entanto, há preferências temáticas na LC que a distinguem das abordagens funcionalistas (além, é claro, de sua origem gerativista, que teima em repontar edipianamente mesmo em circunstâncias bastante remotas). São, em geral, considerados definidores da LC os seguintes elementos: 
Cadernos de EsTUDOS LINGǘlsticos (55.1) - Jan./Jun. 2013

i. A prioridade do estudo das estruturas conceptuais, tendência presente na identificação do caráter heterogêneo e complexo das categorias cognitivas, entre as quais as categorias linguísticas, cuja instanciação enseja a manifestação de efeitos de prototipia.

ii. A defesa do "motivacionismo" semântico na explicação da gramática, manifesto no famoso dito langackeriano, segundo o qual "a sintaxe é semântica congelada".

iii. A incorporação como princípio teórico de uma das distinções basilares da psicologia da Gestalt, a saber, a distinção entre Figura e Fundo, aqui apropriada como a diferença entre Base e Perfil, ou entre Cena (Frame) e Perspectiva.

iv. O tratamento das chamadas "significações figurativas" (significações metafóricas e metonímicas) como relações semânticas verificadas entre frames.

v. O reconhecimento enfático do caráter idiomático das expressões linguísticas, que não só explica a diversidade entre as línguas como "emergente do uso" mas também fundamenta a postulação das "gramáticas das construções" .

vi. A revisão do "motivacionismo" semântico da gramática (reminiscente de antigas teses da "semântica gerativa") à vista de descobertas nas neurociências e na biolinguística que desencadeiam, em filosofia, o neomateralismo enativista e, nas ciências cognitivas, a hipótese sobre a corporificação da linguagem e da cognição.

O florescimento programático da "semântica de frames" como "semântica cognitiva" (isto é, como "semântica da compreensão" antes que como "semântica verificacionista") agrega, desde a sua expressão inicial, grande parte destes elementos. A evolução analítica subsequente permitiu, como mostraremos, a substituição de noções propostas independentemente (como as de Esquemas Conceptuais, Esquemas Imagéticos, Modelos Cognitivos Idealizados...) pela ideia de frames, entre si vinculados na rede dos frames.

A noção de frame emerge em linguística como adaptação de postulações teóricas de Minsky (em Inteligência Artificial) e de Goffmann (em Sociologia Interacional), no mesmo ano de 1974. Tal como estas reflexões fundadoras, postula que todo processo de significação linguística constitui o enquadramento contextualizado (framing) de uma situação, que se apresenta estruturada por uma constelação de elementos que a distinguem de outras situações.

Assim, compreender o conceito de hipotenusa requer a evocação cognitiva de um TRIÂNGULO RETÂNGULO, assim como raio ou corda presumem CÍRCULO. Observe-se que esses exemplos clássicos, deliberadamente recrutados da conceptualização espacial (da cognição geométrica, apenas secundariamente linguística) são incólumes à redução meronímica (isto é, a uma definição semântica em termos da relação PARTE/TODO): obviamente uma hipotenusa faz parte de um TRIÂNGULO RETÂNGULO, embora pareça menos óbvio que um raio ou uma corda possam ser descritos como "partes" do CÍRCULO. No entanto, ainda que concedamos que assim seja, compreender os conceitos de hipotenusa 
SALOMÃO, TORRENTI e SAMPAIO - A linguística cognitiva encontra a linguística...

ou de raio/corda exige que se tenha em mente as totalidades entre si distintas do TRIÂNGULO RETÂNGULO e do CÍRCULO.

Dentro desta literatura, diz-se que a menção da hipotenusa perfila (ou põe em perspectiva) o frame de TRIÂNGULO RETÂNGULO, de tal modo que este lado do TRIÂNGULO vem a ser salientado, em contraposição aos outros Elementos do Frame (EFs), os CATETOS, que ficam, na ocasião, subfocalizados.

Frames podem ser muito mais complexos: considere-se por exemplo o frame de SEMANA, evocado pelo lexema segunda-feira. Este frame corresponde evidentemente a um modelo cultural (nem todas as sociedades humanas empregam as mesmas unidades calêndricas para organizar a PASSAGEM DO TEMPO, categoria cuja conceptualização, por si, requer uma rede de frames...). O frame de SEMANA herda de um frame mais básico, ou seja o esquema imagético de CICLO, importado pela sucessão linear dos DIAS DA SEMANA, cada um dos quais por sua vez designa um EF. Além disso, para nós, a SEMANA dividese em DIAS ÚTEIS e em FIM DE SEMANA, classificação que expressa a ORGANIZAÇÃO DO TRABALHO nas sociedades capitalistas e corresponde a resultado de luta da classe trabalhadora industrial. Sem levar em conta este último aspecto (da ORGANIZAÇÃO DO TRABALHO), não é possível interpretar adequadamente a Unidade Lexical polilexêmica fim de semana prolongado.

A complexidade interna de um frame resulta de sua participação na rede de frames: um modelo cultural como o conceito de SEMANA herda tanto esquemas imagéticos primários (caso de CICLO) como normas sociais ideologizáveis (caso de ORGANIZAÇÃO DO TRABALHO). É possível que a complexidade resulte da combinação de vários esquemas imagéticos: ENTRAR herda o frame de TRAJETÓRIA e usa os esquemas do CONTÊINER e da relação TRAJETOR/MARCO. O frame de COMPRA À VISTA ordena cronologicamente como seus subframes os frames de ENTREGA DA MERCADORIA e ENTREGA DO PAGAMENTO. O frame de EDUCAÇÃO pode ser concebido na perspectiva do frame do ENSINO ou do frame da APRENDIZAGEM. Como se vê, o enredamento das relações semânticas expressa a infinita capacidade humana de gerar significações.

Estas breves considerações nos ensinam o quanto podem ser ricos e diversificados os frames que viermos a considerar. Dois pontos correlatos merecem destaque:

a. Em primeiro lugar, a postulação dos frames como unidades básicas da teoria semântica cancela a distinção tradicional entre "dicionário" e "enciclopédia", dicotomia fundadora dos limites entre as disciplinas de Semântica e Pragmática. De um lado fica difícil discernir entre conhecimento "linguístico" e "não-linguístico": na verdade, frames são complexas estruturas de conhecimento, verbalizáveis ou não; e, quando verbalizáveis, sensíveis às diferenças idiomáticas entre as línguas do mundo. De outro lado, como a evocação de um frame requer sempre que se assuma sobre ele um específico "ponto de vista", também, sob este ângulo, fica difícil manter em sua abordagem a distinção dicotômica entre Semântica e Pragmática. 
b. Em segundo lugar, é necessário ressaltar que a noção de frame é indispensável para toda semântica inferencialista (que assume com Fauconnier que o "significante não porta o significado mas o guia"). Ainda que reconhecendo a variedade contextualizada do processo de inferenciação (nem todos dispomos dos mesmos frames, nem todas as situações comunicativas os mobilizarão do mesmo modo...), o fato é que, sem frames, é impossível construir a significação discursiva.

É a complexidade interna dos frames que explica a geração de efeitos de prototipia presentes nos chistes fillmoreanos lembrados na literatura: a estranheza que causa falar do Papa como um bachelor, ou a impropriedade de lembrar a viuvez de Liz Taylor... Os papéis sociais referidos (bachelor, viúva) evocam frames que tornam aquelas instanciações incompatíveis, ou, no mínimo, esdrúxulas, não obstante satisfazerem as definições componenciais dos respectivos lexemas.

É ainda a possibilidade de perfilar variavelmente o frame evocado pelo lexema casamento que permitirá compreender expressões como casamento no papel, casamento civil, casamento religioso, casamento gay, casamento aberto, casamento inter-religioso, casamento multirracial... A existência de uma rede de frames evocativa do modelo cultural CASAMENTO nos permitirá lidar com a radialidade destes usos.

Na mesma linha, a complexidade interna dos frames responde pela geração de escalas pragmáticas de efeitos de prototipia, presentes em expressões modalizadas com hedges, tais como um típico professor universitário, um óbvio professor universitário, um improvável professor universitário... A investigação de Machado (2011) mostra que este processo é também desencadeável via morfologia lexical, o que é atestado pela superlativação de Adjetivos evocadores de Estados Absolutos, como em solteiríssimo, gravidíssima, formadíssimo, etc. Em todos estes casos, a multiplicidade das situações referenciadas decorre da variação no perfilamento dos Elementos do Frame.

Entre todas estas possibilidades, avultam como de particular interesse as diferenças de perspectivas sobre um frame expressas pelas alternâncias de valências das Unidades Lexicais, assim, considerado o par mínimo Ela arriscou sua vaga no Mestrado versus Ela arriscou ser reprovada no Mestrado, o lexema arriscar evoca, nos dois casos, o mesmo frame de RISCO, mas, no primeiro caso, perfila os EFs PROTAGONISTA e RECURSO enquanto, no segundo caso, perfila os EFs PROTAGONISTA e DANO. As diferenças de perfilamento praticadas devem-se a diferentes instanciações dos Elementos do Frame nas posições sintáticas nucleares (Sujeito e Objeto Direto).

Como sabemos, a percepção do caráter sistemático das correspondências entre funções sintáticas (Sujeito, Objeto...) e funções semânticas (Agente, Paciente...) é fundadora da tradição gramatical. A hipótese gerativa, na sua versão original, a descarta mas ela ressurge com força em meados da década de sessenta, especialmente no capítulo seminal de Fillmore, The case for case. A semântica de frames a abraça programaticamente como elemento crítico da conexão entre semântica lexical e semântica proposicional. 
SALOMÃO, TORRENTI e SAMPAIO - A linguística cognitiva encontra a linguística...

$\mathrm{Na}$ verdade, do ponto de vista linguístico, este é o aspecto mais atraente da semântica de frames: a saber, a abordagem da dimensão sintagmática da significação lexical, até então tratada, especialmente pela semântica estruturalista, apenas em termos de sua dimensão paradigmática (que se expressa nas relações lexicais de sinonímia, antonímia, hiponímia, meronímia...).

Como a variedade das valências de uma Unidade Lexical (UL) instancia mudanças no enquadramento do frame evocado por aquela UL, mais uma vez fica difícil dissociar nesta abordagem o que é Semântica do que é Pragmática; o que é Léxico do que é Gramática; o que é Sentença do que já é Discurso.

Eis porque dissemos no início desta seção que a semântica de frames constitui a mais importante hipótese sobre a significação dentro da LC, de certo modo subsumindo e fundamentando todas as demais abordagens sobre outros aspectos da significação.

\section{O PROJETO FRAMENET}

As décadas de oitenta e de noventa assistiram, no cenário mundial, ao florescimento de grandes empreendimentos lexicográficos motivados seja por situações políticas (como a emergência da União Europeia com inéditas necessidades de relações interlinguísticas), seja pela evolução das tecnologias da informação que definiram um novo horizonte de possibilidades para os léxicos eletrônicos. Neste quadro, figura com destaque a cooperação entre Fillmore e Atkins, que desencadeia a utilização da Semântica de Frames como fundamento teórico de ações no campo da lexicografia prática.

Tais ações estão na origem do projeto FrameNet, iniciado oficialmente em 1997, no International Computer Sciences Institute, em Berkeley, cuja identificação completa encontra-se no site http://framenet.icsi.berkeley.edu.

São objetivos principais deste projeto:

(i) descrever Unidades Lexicais (ULs) a partir dos frames que evocam, frames que são identificados em termos dos Elementos de Frame (EFs) que crucialmente os constituem;

(ii) validar tais descrições através de pesquisa em corpora;

(iii)determinar as possibilidades combinatórias das ULs pesquisadas, anotando, nas sentenças extraídas dos corpora, em camadas, quais são os EFs expressos por cada sintagma, bem como seu Tipo Sintagmático (TP) e Função Gramatical (FG);

(iv) disponibilizar os resultados da anotação na forma de entradas lexicais, as quais sumarizam os possíveis padrões de valência de cada UL;

(v) e definir as relações entre frames, mostrando, por exemplo, em que medida um frame é uma elaboração de outro ou se depende de outro [26], relações representadas via ferramenta FrameGrapher, como se pode verificar no site do projeto FrameNet. 
Cadernos de EsTUDOS LINGǘlsticos (55.1) - Jan./Jun. 2013

Duas metodologias de anotação são utilizadas pela FN: a lexicográfica e a de texto corrido [27]. Na primeira, que é praticada no projeto FrameNet Brasil, levantam-se as ULs que evocam determinado frame: estas são, então, anotadas, com a identificação da realização sintática dos EFs do frame em termos de seus Tipos Sintagmáticos e Funções Gramaticais. O resultado desse primeiro processo pode ser visto na Figura 1, que mostra a anotação da sentença hipotética "Paulo jogou a bola para fora do campo", na qual a UL alvo jogou evoca o frame CAUSAR_MOVIMENTO.

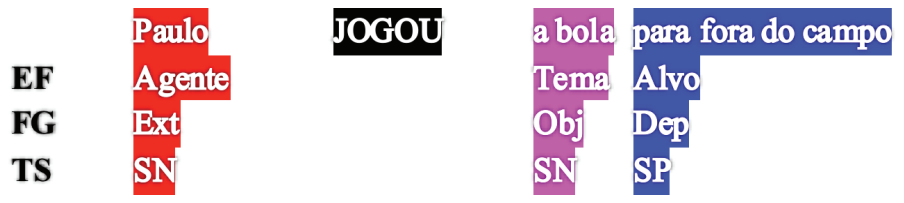

Figura 1: Exemplo de anotação lexicográfica da UL jogar evocando o frame de CAUSAR_MOVIMENTO

Uma definição resumida do frame em questão poderia ser proposta da seguinte forma:

CAUSAR_MOVIMENTO: Um AGENTE faz com que um TEMA se submeta a um movimento de translação. O movimento deve sempre ser descrito em relação a uma ORIGEM, CAMINHO e/ou ALVO.

AGENTE [Agt]: O AGENTE é aquele cuja ação causa o movimento do TEMA. O AGENTE geralmente é realizado como Argumento Externo.

TEMA [Thm]: O EF TEMA geralmente é um SN Objeto.

ALVO [Goal]: O EF ALVO é o ponto no qual o TEMA vai parar como resultado do movimento.

Na segunda metodologia de anotação, praticada no projeto FrameCorp, na UNISINOS, toma-se um texto e faz-se a anotação de todas as ULs que evocam frames, criando-se árvores de dependência que relacionam as ULs - e seus papéis em cada um dos frames evocados na sentença - entre si.

Ambas as metodologias têm como resultado uma base de dados linguísticos estruturados a partir de cenas relevantes para a compreensão que os falantes têm do mundo que os cerca. Por ser construída respeitando uma metodologia que permite o tratamento computacional de sua base de dados, a FrameNet possibilita, em especial quando encarada como (ou em interface com) uma ontologia, o desenvolvimento de soluções em informática muito relevantes em um cenário global caracterizado tanto pelo excessivo volume de informação a ser tratada quanto pelo fato de que tal informação precisa ser traduzida para vários idiomas.

É importante mencionar que, atualmente, baseados na FrameNet, estão em desenvolvimento recursos lexicais em diferentes línguas: para o Espanhol http:// gemini.uab.es:9080/SFNsite, o Alemão http://www.laits.utexas.edu/gframenet/, o Japonês http://jfn.st.hc.keio.ac.jp/, o Sueco http://spraakbanken.gu.se/eng/swefn e, num estágio mais inicial, o Mandarim .

À semelhança de seus congêneres, o projeto $\mathbf{F N ~ B r}$, de anotação lexicográfica, está criando para o Português do Brasil um recurso lexical accessível on line, 
SALOMÃO, TORRENTI e SAMPAIO - A linguística cognitiva encontra a linguística...

com base na semântica de frames e apoiado em evidência extraída de corpus. Atualmente, como se pode constatar, visitando o site do projeto, já se disponibiliza ao conhecimento público uma fração dos frames e unidades lexicais anotados a partir de um corpus de aproximadamente setenta e dois milhões de tokens, representativos de uma diversidade de usos exclusivamente do Português do Brasil.

Uma questão a considerar abordaria a relevância de construir um recurso lexical como a FrameNet em suas diversas versões linguísticas, frente a alternativas potencialmente concorrentes _ dicionários eletrônicos, ontologias ou o recurso lexical WordNet.

A universalização das práticas de leitura e escrita no computador levou, nas duas últimas décadas, à produção de dicionários eletrônicos, que, num primeiro momento, pouco se diferenciaram de suas contrapartes impressas: a grande distinção consistia em, ao invés de perscrutar linearmente uma lista organizada por ordem alfabética, acessar diretamente a informação desejada mediante a digitação do lexema-alvo: o retorno, entretanto, não se diferenciava do conteúdo oferecido nas versões impressas, na medida em que a informação suprida correspondia a uma listagem dos sentidos associáveis ao lexema, às vezes ilustrados por alguns exemplos.

Um problema frequentemente observado nestes recursos lexicais é a indistinção nos verbetes entre sinônimos do lexema e as definições de seus sentidos. Vide a entrada lexical para o lexema contemplar oferecida pelo dicionário Aulete, dicionário monolíngue do Português, disponível eletronicamente:

- (lat. contemplare) vtd

1. Olhar, observar com atenção: '034; Afrouxaram os braços e cada lutador recuou para contemplar o seu adversário'034; (José de Alencar). Do alto da cátedra, contemplava os discípulos. Contemplara, nas paisagens maravilhosas, as residências campesinas. Como o Divino Mestre, contempla os homens pelo prisma da caridade. vtd

2. Ver, admirar com o pensamento: Contemplamos boquiabertos o desenfreado aumento do custo de vida. vtd

3. Imaginar, supor: '034; E assim, está o coração, cada ano, cada dia, cada hora, sempre alimentado em contemplar o que não vê'034; (Rui Barbosa). vint

4. Meditar, reflexionar em: '034; Se contemplo como fui destas praias apartado... '034; (Luís de Camões). vpr

5. Mirar-se, ver-se ao espelho com desvanecimento: Ficava muito tempo a contemplar-se vaidosamente. vtd

6. Conferir a alguém alguma coisa, como prêmio ou prova de consideração: '034; Ao morrer, contemplou todos os seus criados'034; (Morais).

Reconhecendo, embora, o caráter polissêmico do lexema e ilustrando, com exemplos, a pluralidade de seus usos, o verbete do Aulete mistura, em quase todas as alíneas, sinônimos (e.g. olhar, al. 1) e definições ("observar com atenção", 
Cadernos de EsTUDOS LINGǘsTICOS (55.1) - Jan./Jun. 2013

al.1). Há alíneas, como a 3, em que a definição sequer figura. Há casos em que, por falta de explicitação de critério, é difícil discernir a diferença entre os sentidos descritos (e.g. alíneas 1 e 5); em outros casos, a distinção, de natureza metafórica, também não é explicitada (e.g. alíneas 1 e 2).

A situação caracterizada para o Aulete replica-se em grandes linhas nos outros dicionários comerciais disponíveis eletronicamente para o Português (Houaiss, Michaelis, Morais...)

Este problema é, com êxito, resolvido para o Inglês, pelo recurso lexical WordNet (http://wordnet.princeton.edu/), concebido e desenvolvido inicialmente sem finalidades lexicográficas, mas tratado desde o seu aparecimento como uma tecnologia de referência para a elaboração de léxicos em várias línguas por distinguir, com rigor, definições e relações lexicais. A influência desta atitude é perceptível na elaboração de recursos lexicais para o Inglês, disponibilizados eletronicamente como o dictionary.com, que separa judiciosamente definições e sinônimos, além de disponibilizar via hipermídia o acesso à pronúncia falada do lexema e informações sobre sua história e etimologia.

De todo modo, os dicionários eletrônicos restringem à sinonímia sua representação das relações de que o lexema participa. Esta escassez é também superada vantajosamente pelas propostas constantes do projeto WordNet, como ilustrado abaixo para o lexema do Inglês justice:

WordNet Search - 3.0 - WordNet home page - Glossary - Help

Word to search for: Display Options: Key: "S:" = Show Synset (semantic) relations, "W:" = Show Word (lexical) relations

\section{Noun}

$\underline{\mathrm{S}}$ : (n) justice, justness (the quality of being just or fair)

direct hyponym / full hyponym

$\underline{\mathrm{S}}$ : (n) fairness, equity (conformity with rules or standards) "the judge recognized the fairness of my claim"

S: (n) right, rightfulness (anything in accord with principles of justice) "he feels he is in the right"; "the rightfulness of his claim"

direct hypernym / inherited hypernym / sister term

antonym

$\underline{\text { W: }}$ (n) injustice [Opposed to: justice] (the practice of being unjust or unfair)

derivationally related form

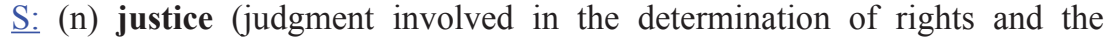
assignment of rewards and punishments)

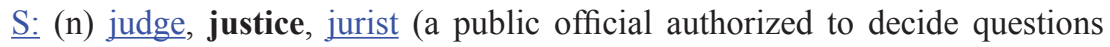
brought before a court of justice)

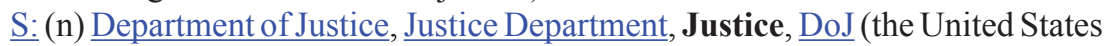
federal department responsible for enforcing federal laws (including the enforcement of all civil rights legislation); created in 1870)

Segundo a metodologia do projeto WordNet, estabelece-se a existência dos diversos sentidos de um lexema desde que se descubra, para cada um deles, um 
SALOMÃO, TORRENTI e SAMPAIO - A linguística cognitiva encontra a linguística...

par de sinônimos (um synset), critério que permite enfrentar objetivamente uma das maiores dificuldades presentes em qualquer empreendimento lexicográfico: a decisão entre "dividir" ou "enxugar" nuanças da significação.

A partir da detecção dos diversos sentidos, desenha-se então a rede de relações das quais o lexema participa. A representação acima ilustra a rede em que se insere o lexema justice: a sinonímia com justness, a polissemia com justice, formando um synset com judge ou com Department of Justice, a antonímia com injustice, e a hiponímia com o par fairness/equity. Observe-se ainda que, via hipermídia, é possível acessar diretamente todos os lexemas integrantes da "rede de palavras" caracterizada.

As vantagens do recurso lexical WordNet estimularam a construções de WordNets multilíngues, como é o caso da EuroWordNet http://www.illc. uva.nl/EuroWordNet/, que prevê o tratamento das correspondências lexicais interlinguísticas como um caso específico de sinonímia. Estabelecer estas correspondências prevê, obviamente, a construção de bases de dados linguísticos para as diversas línguas envolvidas (no caso, Alemão, Espanhol, Estoniano, Francês, Holandês, Italiano, e Tcheco).

Uma facilidade operacional introduzida consistiu em usar a WordNet original, de Princeton, como recurso lexical de referência, adotando-se os synsets criados para o Inglês e traduzindo os "sentidos" da WordNet original para a língua-alvo. Como observam Linde-Usiekniewicz e Olko, esta iniciativa nada tem de trivial já que as bases de dados correlacionadas têm como nódulos lexemas, que não necessariamente (na verdade, bem raramente) compartilham relações de polissemia.

Sob este aspecto, o uso da FrameNet como metalíngua afigura-se mais vantajoso já que os frames, como unidades conceptuais, são a princípio evocáveis por Unidades Lexicais em diferentes línguas sem que características idiossincraticamente linguísticas tornassem impossíveis o tipo de indexação prefigurada no caso de projetos multilinguísticos como a EuroWordNet.

Como observa Boas, tratando da produção de um dicionário bilíngue InglêsAlemão,

já que os frames codificam as relações semânticas e as constelações de funções que conectam os EFs individuais, o inventário dos EFs será, então, empregado para comparar a realização de uma determinada combinação de informação sintática e semântica da língua-fonte na língua-alvo.

A Figura 2 ilustra de que modo é possível usar um frame para estabelecer correspondências entre as Unidades Lexicais intertradutíveis, a saber, os Verbos argue e streiten, respectivamente do Inglês e do Alemão: 


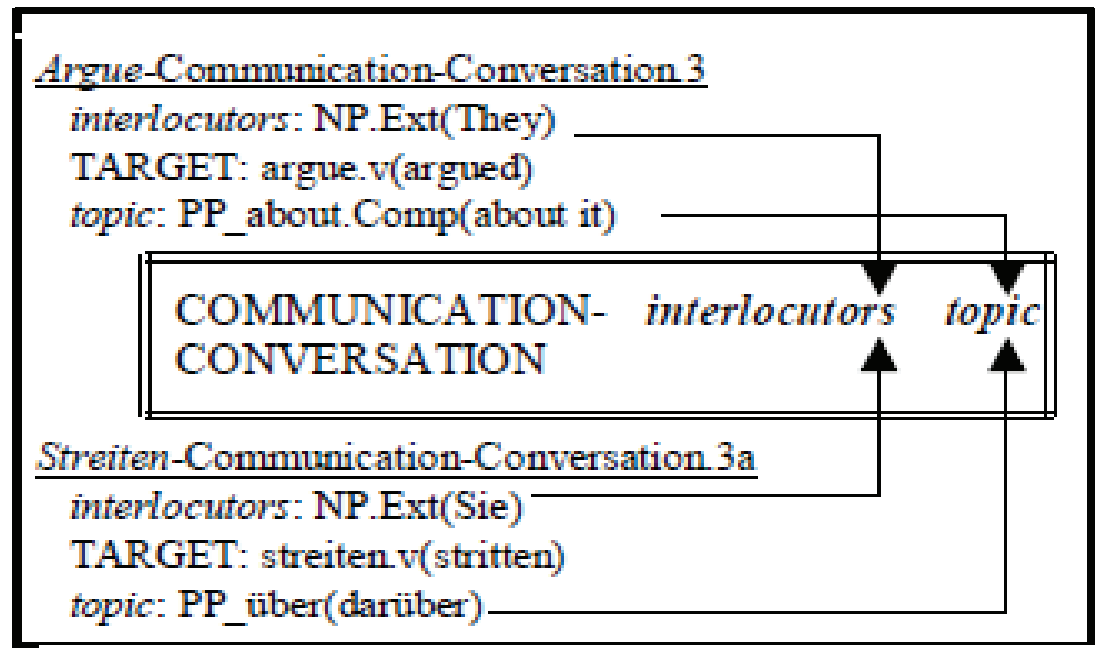

Figura 2. Emprego de frames para o estabelecimento de correspondências entre ULs

Observe-se que as microfunções semânticas válidas na caracterização do frame Communication_conversation (respectivamente os EFs INTERLOCUTORES e TÓPICO) são também anotadas quanto a suas possibilidades de realização sintática: seu Tipo de Sintagma (NP, PP) e sua Função Gramatical (Ext., Comp.).

Os casos de polissemia, problemáticos para as WordNets multilíngues, aqui seriam facilmente enfrentados, dado que a categoria descritiva da FrameNet é a Unidade Lexical (definida como emparelhamento de um lexema com um frame) e não o próprio lexema.

É claro que as línguas variam quanto a seus padrões de lexicalização, como Talmy demonstrou para os verbos de movimento nas línguas românicas em contraposição aos verbos correspondentes nas línguas germânicas; este fato não é, a princípio, um problema para dicionários multilíngues baseados em frames. A diferença, como Talmy deixa claro, não está nos padrões conceptuais (ou seja, nos frames) e sim nos padrões de lexicalização: línguas germânicas lexicalizarão frames de Movimento que incluirão necessariamente um EF nuclear de MANEIRA; línguas românicas lexicalizarão Movimento com um EF nuclear de DIREÇÃO.

É inteiramente possível construir um dicionário multilíngue baseado em frames que se conecte de modo elegante e complementar com o recurso lexical oferecido pela WordNet: a conexão interlinguística será feita pelos frames e as conexões lexicais intralinguísticas providenciadas pelas WordNets das línguas em questão.

Para o Português, a versão disponível da WordNet é desenvolvida em Portugal http://www.clul.ul.pt/clg/wordnetpt/index.html, sob a direção da Professora Palmira Marrafa. No Brasil, o Professor Bento Carlos Dias da Silva, da UNESP, vem desenvolvendo desde 2003 projeto de criação de uma WordNet voltada para a nossa modalidade de Português. 
SALOMÃO, TORRENTI e SAMPAIO - A linguística cognitiva encontra a linguística...

Concluindo, entendemos que a FrameNet possa vantajosamente subsidiar a produção de dicionários eletrônicos, inclusive multilíngues, recorrendo à utilização da WordNet para criar recursos lexicais mais abrangentes e funcionalmente mais poderosos. $\mathrm{Na} \mathrm{FN} \mathrm{Br}$, encontra-se em desenvolvimento um projeto cujo objetivo é o de criar um desses dicionários. Voltamo-nos a ele na próxima seção.

\section{O PROJETO COPA 2014}

O projeto Copa 2014 FrameNet Brasil propõe desenvolver, em meio eletrônico, um dicionário temático trilíngue (Português - Inglês -Espanhol) abrangendo os domínios do Futebol e do Turismo. Tal dicionário, com foco no uso humano, terá como audiência privilegiada a imprensa esportiva internacional, pessoas envolvidas na organização da Copa do Mundo FIFA 2014 e na recepção aos turistas estrangeiros, além dos próprios turistas. Em sintonia com as mudanças correntes na área das Tecnologias da Informação, o dicionário será um recurso lexical acessível eletronicamente de qualquer parte do mundo.

A proposta do projeto Copa 2014 FN Br baseia-se na experiência de constituição de um dicionário do domínio do Futebol fundado na Semântica de Frames: o Kicktionary (SCHMIDT, 2006; 2007). Trata-se de um recurso online trilíngue (Inglês, Francês e Alemão) construído por Thomas Schmidt e disponível para consulta através do endereço http://www.kicktionary.de. No Brasil, a Profa. Dra. Rove Chishman, parceira da equipe da FN Br no desenvolvimento do Copa 2014, coordena, no âmbito do Projeto FrameCorp, o Kicktionary-Br, projeto que tem como objetivo criar a contraparte desse dicionário para o Português do Brasil.

Segundo Schmidt (2007, p. 189),

\footnotetext{
O objetivo geral no desenvolvimento do Kicktionary era explorar de que forma as teorias linguísticas sobre a semântica lexical (especialmente as abordagens da FrameNet e da WordNet para a lexicografia), os métodos da linguística de corpus e a tecnologia de hipermídia podem ajudar na construção de recursos lexicais que sejam melhores que os dicionários tradicionais de papel (ou bons de uma maneira diferente).
}

Assim, o Kicktionary (e, por extensão, o Kicktionary-Br) trabalha a partir da integração entre um recurso lexical baseado na Semântica de Frames (FrameNet) e as relações entre palavras propostas pela WordNet. Tal integração possibilita, do lado da WordNet, tanto o tratamento das relações comumente encontradas em um dicionário monolíngue (sinonímia, antonímia e hiperonímia, por exemplo) quanto o tratamento das relações entre traduções de um dado conceito em diversas línguas, objetivo central dos dicionários multilíngues. Do ponto de vista da FrameNet, possibilita que o usuário realize suas consultas a partir de cenas relevantes para suas necessidades comunicativas, perfilando a relação entre seus vários participantes.

Em termos práticos, a integração da FrameNet com a WordNet no âmbito de um dicionário eletrônico multilíngue dos domínios do Futebol e do Turismo oferece 
ao usuário não só a possibilidade de verificar qual a tradução, na sua língua-alvo, de termos como impedimento ou visita guiada; mas, ainda, as possibilidades de:

i. encontrar sinônimos para esses termos;

ii. encontrar hiperônimos para esses termos, tais como lance ou atividade turística;

iii. nomear os participantes envolvidos em cada uma das cenas - tais como atacante, zagueiro e bandeirinha, no primeiro caso; ou guia turista e atração, no segundo - bem como visualizar a relação entre eles.

Para gerar esse tipo de produto final, dicionários como o Kicktionary - e como será o Copa 2014 - trabalham com a anotação de sentenças coletadas em corpora traduzidos ou equivalentes. Corpora traduzidos são aqueles em que um mesmo texto foi produzido em mais de um idioma; já os equivalentes são compostos por textos, geralmente de um mesmo gênero, que foram produzidos nas línguas-alvo do dicionário de forma independente, ou seja, textos que se referem a um mesmo domínio (Futebol ou Turismo, no caso), publicados em mídias similares (revistas ou sites especializados, por exemplo), mas que não constituem traduções uns dos outros. O Kicktionary fez uso de ambos os tipos de corpora (cf. SCHMIDT, 2006; 2007). Como corpora traduzidos, utilizam as reportagens sobre partidas de futebol encontradas no site da Federação Europeia de Futebol (UEFA) e, como corpora equivalentes, usam reportagens de jornais esportivos e transmissões radiofônicas de jogos.

Uma vez que os textos em Português no site da UEFA são escritos na variedade europeia da língua, o Kicktionary-Br já trabalha com a constituição de um corpus equivalente (cf. CHISHMAN, 2009b) para o domínio do Futebol. Para o domínio do Turismo, encontra-se em fase final de construção um corpus traduzido, coletado a partir de diversos sites governamentais focados na Copa do Mundo ou no potencial turístico brasileiro. A constituição desse corpus é apresentada na Tabela 1.

\begin{tabular}{|l|c|c|c|}
\hline Site & \multicolumn{3}{|c|}{ Tokens por Idioma } \\
\hline URL & Português & Espanhol & Inglês \\
\hline $\begin{array}{l}\text { Brazilian Tourism Portal (BTP) } \\
\text { http://www.braziltour.com }\end{array}$ & 58.059 & 58.437 & 56.164 \\
\hline $\begin{array}{l}\text { Brasil das Copas (BC) } \\
\text { http://www.brasil.gov.br/ } \\
\text { copadomundo }\end{array}$ & 7.356 & 7.754 & 7.409 \\
\hline $\begin{array}{l}\text { FIFA (FF) } \\
\text { http://www.fifa.com/worldcup }\end{array}$ & 431.664 & $\begin{array}{c}\text { em } \\
\text { construção }\end{array}$ & $\begin{array}{c}\text { em } \\
\text { construção }\end{array}$ \\
\hline
\end{tabular}

Tabela 1: Corpora traduzidos já compilados para a Copa 2014. O número de tokens por idioma representa um valor aproximado. 
SALOMÃO, TORRENTI e SAMPAIO - A linguística cognitiva encontra a linguística...

Será constituído também um corpus equivalente, a partir de textos publicados em revistas de viagem, revistas de bordo de companhias aéreas, cadernos especializados de jornais e blogs de viajantes. A diversidade de esferas comunicativas e gêneros textuais é importante na constituição do corpus para que o dicionário possa fornecer evidências que sejam, de fato, representativas dos usos que os falantes fazem dos idiomas-alvo.

Constituído o corpus, a metodologia do Kicktionary prevê que sejam realizadas as anotações no que tange aos frames e cenas evocados pelas Unidades Lexicais encontradas nas sentenças. Ao contrário do que ocorre na FrameNet (cf. RUPPENHOFER et al., 2010), em que primeiro define-se o frame - com sua descrição geral e seus Elementos (EFs) - para que depois sejam buscadas as ULs que o evocam - portanto, uma metodologia de análise top-down -, no Kicktionary emprega-se uma metodologia bottom-up (cf. SCHMIDT, 2006; 2007), ou seja, a partir da atribuição de papéis aos elementos relacionados a uma UL, define-se o frame e a cena evocados por aquela UL, os quais serão descritos com base nos dados já anotados.

Schmidt (2006, p.2) afirma que, por se restringir a um domínio específico, o Kicktionary, ao contrário da FrameNet (que busca ser um recurso lexical que abrange todas as temáticas e domínios), pôde ser construído seguindo-se o caminho inverso de análise. Isto significa que se partiu de uma lista de termos relacionados ao domínio do Futebol para, a partir dos dados emergentes da anotação, adicionarse estrutura a essa lista, propondo as relações entre as palavras. Essa metodologia bottom-up permitiu uma análise mais minuciosa e menos direcionada pelas intuições iniciais do analista, uma vez que, caso se definisse primeiro a estrutura cognitiva, para que, só posteriormente, se verificasse como ela se manifesta linguisticamente, correr-se-ia o risco de deixar de lado algum aspecto relevante dos usos linguísticos relacionados ao Futebol.

O domínio do Turismo se comporta de maneira semelhante ao do Futebol no que tange a esse aspecto, assim é que, para o Copa 2014, a metodologia bottom-up também tem sido adotada. Dessa forma, tanto a estrutura de relações de sinonímia, polissemia, hiperonímia, troponímia, meronímia, holonímia (típicas da WordNet) quando as relações entre Elementos de Frame (características da FrameNet) serão representadas posteriormente ao levantamento e anotação das ULs.

A título de exemplo, considere-se o trabalho em desenvolvimento por Gamonal (GAMONAL, 2011; GAMONAL \& TORRENT, 2012), acerca dos frames relacionados à experiência turística. Até o presente momento, foram levantadas, nos corpora oriundos dos sites Brazilian Tourism Portal e Brasil das Copas, ocorrências das ULs abrigar, apreciar, atrair, destacar(-se), oferecer, possuir, surpreender e visitar. Levantadas as sentenças em que os lemas de tais ULs verbais ocorrem, são selecionadas para análise e anotação aquelas nas quais os verbos em questão evocam frames relacionados ao domínio da experiência do turista ${ }^{5}$. Sentenças desse tipo são apresentadas de (1) a (4) abaixo:

5. Sentenças em que os verbos selecionados evocam frames que não são abarcados pelo domínio do Turismo são descartadas, já as que se relacionam a outros sub-domínios, que não a experiência turística, são armazenadas para anotação posterior. 
Cadernos de EsTUDOS LINGǘlsticos (55.1) - Jan./Jun. 2013

(1) A baía da Ilha Grande abriga uma das maiores concentrações de naufrágios do mundo, sendo uma excelente opção para a prática do mergulho. (BTP)

(2) A beleza do Pantanal atrai visitantes do mundo inteiro, tornando o turismo ecológico muito importante para a região. (BTP)

(3) Olinda oferece aos visitantes algumas das mais belas paisagens do Brasil. (BTP)

(4) O parque [da Serra da Capivara] é visitado por turistas e estudiosos de todo o mundo. (BTP)

O trabalho de anotação se inicia, seguindo-se a metodologia definida pela FrameNet (cf. RUPPENHOFER et al., 2010) para a anotação lexicográfica. Assim, as sentenças acima recebem as tags para os Elementos de Frame, Tipos Sintagmáticos e Funções Gramaticais, conforme demonstrado na Figura 1. Considerando-se apenas a camada dos EFs, a anotação produz o resultado demonstrado de (1a) a (4a).

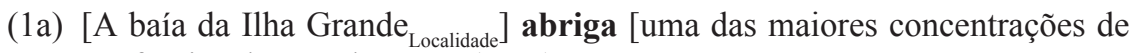
naufrágios do mundo $\left.{ }_{\text {Atração }}\right]$. (BTP)

(2a) [A beleza do Pantanal Atração/Localidade $_{\text {atrai [visitantes do mundo inteiro }}$ Turista $]$. (BTP)

(3a) $\left[\right.$ Olinda $\left._{\text {Localidade }}\right]$ oferece $\left[\right.$ aos visitantes $\left._{\text {Turista }}\right]$ [algumas das mais belas paisagens do Brasil ${ }_{\text {Atração }}$. (BTP)

(4a) [O parque da Serra da Capivara ${ }_{\text {Atração }}$ é visitado [por turistas e estudiosos de todo o mundo Turista $_{\text {. }}$ (BTP)

Definidos os EFs, podem ser adotados dois caminhos analíticos distintos: ou se enquadra a UL alvo em um frame já existente na FrameNet, ou se constrói um novo frame que dê conta dessa UL. Esse passo da análise não ocorre para os frames relacionados ao domínio do Futebol, uma vez que, quando da constituição do Kicktionary (SCHMIDT, 2006; 2007), eles foram criados seguindo-se a metodologia bottom-up, não havendo qualquer referência anterior para o enquadramento das ULs.

A FrameNet já possui alguns frames relacionados ao domínio do Turismo. Conforme levantamento feito por Tosqui (2007), os frames Board_vehicle, Hospitality, Provide_lodging, Receive_visitor_scenario, Travel, Use_vehicle, Vehicle, Visiting_scenario_arrival, Visiting_scenario_stay e Visitor_departure, além de Touring (não citado pela autora), descrevem situações relacionadas ao Turismo. Assim, com base nos EFs perfilados pelas ULs alvo nas sentenças anotadas, pode-se propor que determinada UL evoca um dos frames já existentes, evitando-se, assim, a criação desnecessária de um novo frame. A título de exemplo, observe-se a descrição de Touring, traduzida para o Português por Gamonal (2011). 
SALOMÃO, TORRENTI e SAMPAIO - A linguística cognitiva encontra a linguística...

FRAME: TURISMO

Definicão:

\section{Elementos de Frame:}

\section{Nucleares:}

Atração

Turista

\section{Não-Nucleares:}

\section{Co-participante}

\section{Descrição}

Duração

Base

Modo

Meio

Iteração específica

Lugar
Um Turista visita ou experiencia uma Atração, um local com uma história pecualiar ou o caráter individual reconhecido socialmente, com o objetivo de ver e aprender sobre ele. Normalmente, a Atração tem uma fonte de informação tal como - um guia, panfletos ou displays.
O local peculiar socialmente reconhecido que o turista visita.

O indivíduo que está buscando uma experiência em uma Atração.

O Co-participante é quem participa de modo coordenado, no caso em uma turnê com o turista.

O estado do Turista ou da Atração durante a visita.

A quantidade de tempo que dura a atividade de turismo.

O background perceptivo contra o qual a Atração é experimentada pelo Turista.

Qualquer descrição dos detalhes do evento em termos de como eles se comparam com outros eventos (da mesma forma) ou em termos de como o estado do Turista os afeta (felizmente, distraidamente).

O Meio indica o método de turismo que está sendo usado para participar da viagem.

Expressões marcadas com este EF extratemático modificam um uso não iterativo do alvo e indicam que ele é concebido como incorporado dentro de uma série de eventos ou estado similares.

O local onde o turismo acontece.

Alguma ação que o Turista está tentando realizar com o turismo. Isso geralmente é (no mínimo) para fins de entretenimento e aprendizado.

O tempo em que o turismo acontece.

A partir da atribuição de EFs aos sintagmas das sentenças de (1a) a (4a), pode-se concluir que a UL visitar pode ser enquadrada no frame de Turismo. Obviamente, para que se chegue a essa conclusão, faz-se necessária a análise de mais sentenças contendo a UL (novamente, veja-se GAMONAL, 2011). Entretanto, mesmo com a análise de apenas uma sentença por UL, já é possível que se perceba que abrigar, atrair e oferecer, perfilam EFs de maneira diferente de visitar. Tal diferença é, a princípio, devida a uma alteração de perspectiva: enquanto visitar evoca a experiência turística sob a ótica do Turista, as outras três ULs o fazem pela perspectiva da Atração. 
Alterações de perspectiva são uma das principais razões que motivam a criação de frames (cf. RUPPENHOFER et al., 2010). O clássico exemplo da transação comercial ilustra muito bem de que forma a alteração de perspectiva pode criar novos frames. Em trabalho acerca da cena cognitiva do "evento comercial", Fillmore (1977) demonstrou essa possibilidade. Nessa cena, há uma pessoa - o Vendedor - interessado em trocar mercadorias por dinheiro; outra - o Comprador - interessada em trocar dinheiro por mercadorias; além dos itens comprados ou vendidos - as Mercadorias - e do Dinheiro. O conjunto dos verbos ingleses buy, sell, pay, charge, entre outros, evoca essa cena, adotando a perspectiva de um dos elementos que a compõem.

De volta aos exemplos, temos que, em (1a), não é nem mesmo possível postular a existência de um EF Turista para a valência do verbo abrigar. Nesse sentido, a alteração de perspectiva se dá de forma tão marcada que, mesmo a partir de uma única sentença, nota-se a necessidade de se criar um novo frame. Nesse caso, poder-se-ia propor, com base nos EFs anotados para a sentença (1a), o frame de Potencial_turístico, no qual uma Localidade possui uma Atração relevante para o turismo. Casos como o de (1a) ilustram como se deve proceder, na metodologia de trabalho adotada para o Copa 2014, quando uma determinada UL não se enquadra da descrição de um frame já existente.

Embora, como já dito, o foco do Copa 2014 sejam usuários humanos, é impossível desconsiderar a fronteira da web semântica no desenvolvimento deste recurso. Nestes termos, face à amplidão da informação circulante na web e o correlato imperativo de promover a legibilidade de textos por máquinas, é necessário discutir a perspectiva de interface entre o Copa 2014 e as ontologias.

O projeto matriz, no ICSI, já contempla desdobramentos nesta direção, conforme se pode constatar no http://www.ontologyportal.org/, via trabalho de Jan Scheffczy, buscando estabelecer ligações entre a FN e a ontologia SUMO. No que se refere à $\mathrm{FN} \mathrm{Br}$, a conexão com ontologias (especialmente a ontologia DOLCE) é objeto da tese de doutoramento de Alexandra Moreira, em desenvolvimento.

O fato de a FrameNet constituir um "sistema de conhecimento" (validado pela sua conexão, verificada em corpus, com dados linguísticos) a habilita a interagir com outros "sistemas de conhecimento" propostos com diferentes tipos de ambição e, por isso mesmo, menos aptos a dialogar com as línguas naturais. Nestes termos a FN pode ser considerada um sistema análogo às ontologias, embora muito menos axiomatizado (por exemplo, do que a DOLCE) e muito mais denso em termos da especificidade do conhecimento representado. No caso do Copa 2014, por exemplo, o nível de conhecimento representado exibirá altíssimo teor de particularidade.

Um desafio, então, que se coloca é o de "reestruturar" o presente desdobramento da FN Br, para usar a terminologia empregada em Prévot, Borgo e Oltramari (2005), caracterizando as possibilidades de interface entre ontologias e recursos lexicais: a reestruturação ontológica da $\mathrm{FN} \mathrm{Br}$, no que se aplica ao projeto Copa 2014, consistiria em aplicar-lhe as restrições formais que caracterizam o desenho de ontologias (GUARINO \& WELTY, 2004), introduzindo nele, por exemplo, a distinção ontológica entre função e tipo. 
SALOMÃO, TORRENTI e SAMPAIO - A linguística cognitiva encontra a linguística...

A nós nos parece que, além das perspectivas de futuro postas para esta classe de empreendimentos, a elaboração ontológica do Copa 2014, em qualquer caso, amplia as possibilidades de utilização da Semântica de Frames como metalíngua.

\section{O PROJETO FRAMES E CONSTRUÇÕES}

Outra frente de trabalho no âmbito da FN-Bré o projeto Frames e Construções. Tal projeto objetiva a implementação de um Constructicon, entendido como uma base de dados de construções do PB, eletronicamente acessível, nos moldes da base de descrição lexical da FN. O projeto Frames e Construções também encontra sua inspiração no trabalho desenvolvido pela equipe coordenada por Charles Fillmore, que procura desenvolver, desde 2006, um Constructicon do inglês, com o objetivo de identificar e catalogar construções gramaticais daquela língua (cf. FILLMORE, LEE-GOLDMAN \& RHODES, no prelo).

Assim, se as entradas da $\mathrm{FN}-\mathrm{Br}$ são unidades lexicais, que remetem a descrições de frames e a uma lista de Elementos de Frame (EFs), as entradas do Constructicon descrevem as construções e seus componentes, identificando os elementos sintáticos que caracterizam a construção - os Elementos da Construção (CEs). A ideia é que o Constructicon também ofereça informações sobre a contribuição semântica da construção, especifique relações entre construções e apresente sentenças atestadas anotadas que ilustrem ocorrências da construção. De fato, a proposta de implementar uma base de dados desse tipo justifica-se por diversos fatores. Desde o pressuposto assumido pelos pesquisadores da área de que existe uma continuidade entre gramática e léxico (cf. SALOMÃO, 2002) até as limitações práticas nas quais esbarram os pesquisadores da FrameNet na anotação de texto corrido (FILLMORE, 2008).

Como vimos, nesse tipo de anotação, são anotadas todas as ULs que evocam frames em um dado texto, criando-se árvores de dependência que relacionam tais ULs entre si, assim como seus papéis em cada um dos frames evocados. Contudo, como reconhece Fillmore (2008), mesmo sentenças cotidianas, encontradas em qualquer jornal, tal como "For all the disappointments, posterity will look more kindly on Tony Blair than Britons do today", colocam um grande desafio para essa abordagem. Isso porque um olhar mais atento perceberá que, nessa sentença, além das ULs disappointments, look e today, que parecem evocar, respectivamente, os frames EMOTION_DIRECTED, PERCEPTION_ACTIVE e TEMPORAL_COLLOCATION, existem outros elementos capazes de construir cenários bastante específicos.

Assim, segundo a análise de Fillmore (2008), em "for all the disappointments", há a estrutura for all $X$, que é concessiva, com significado equivalente a 'apesar de X', e parece ser restrita a objetos definidos. Já em “look kindly on” reconhecese um verbo frasal com o significado de 'julgar positivamente'. Nesse caso, o uso idiomático de look no dado contexto, nos obriga a descartar a assunção feita acima de que look evocaria o frame PERCEPTION_ACTIVE. Finalmente, todo trecho da sentença posterior à vírgula constitui uma estrutura comparativa na qual 
Cadernos de ESTUDOS LINGǘlsticos (55.1) - Jan./Jun. 2013

os elementos são comparados em duplo escopo, uma vez que os Britânicos são comparados às pessoas como um todo e o presente é comparado com o futuro, sendo que ambas as noções de 'pessoas como um todo' e 'futuro' encontram-se compactadas na palavra posterity.

O que essa análise revela é que é impraticável querer atribuir, separadamente, a cada uma das palavras que compõem a sentença em causa, a responsabilidade pela evocação dos cenários descritos acima. Exemplo convincente disso é pensar no absurdo de se dizer que a UL look evoca o frame de JUDGMENT. Faz-se necessário, portanto, reconhecer que outros elementos, e não apenas ULs, sejam capazes de evocar frames. O melhor candidato a ocupar esse posto parece ser a Construção.

$\mathrm{Na}$ verdade, o caminho percorrido por Fillmore para chegar ao desenvolvimento da FN apresenta uma profunda interseção com os estudos construcionais da gramática, tendo em vista que os primeiros insights que levaram ao desenvolvimento da Semântica de Frames derivam da tentativa de se criar uma Gramática de Casos, na qual verbos eram agrupados em famílias que compartilhavam valências casuais. Tal tentativa encontra-se na base da chamada "virada construcional dos estudos da gramática", a qual, segundo Salomão (2002, p.67-68), tem suas fundações em três diferentes correntes analíticas.

A primeira delas foi encabeçada por George Lakoff, que, a partir dos estudos sobre redes polissêmicas, estabeleceu a noção de redes construcionais figurativamente motivadas (LAKOFF, 1987). A partir de uma análise das construções dêiticas e existenciais com there em Inglês, o autor propõe que as construções gramaticais tenham, de fato, existência cognitiva, não devendo ser consideradas como meros recursos epifenomênicos. Lakoff ressalta ainda a importância de se levar em consideração a motivação na análise das construções de uma língua e a não-composicionalidade absoluta das construções.

A segunda corrente, ainda de acordo com Salomão (2002), remete, em origem, aos trabalhos do próprio Fillmore sobre idiomas sintáticos codificadores de fórmulas situacionais. A construção com let alone (equivalente ao uso de que dirá em casos como Ele não gosta nem de teatro, que dirá de ópera) serviu de exemplo para tais análises, mostrando que a fórmula situacional da comparação entre dois eventos era indicada por uma forma construcional de encadeamento de duas orações através da expressão conjuntiva let alone (FILLMORE; KAY; O’CONNOR, 1988). Também tributária da proposta construcionista de Fillmore é a própria noção de padrões de valência, hoje empregada pela FrameNet, cujas bases estão fundadas na Gramática de Casos, lançada no seminal The Case for Case (FILLMORE, 1968 [1967]).

O último movimento citado por Salomão (2002) é o derivado dos estudos de Adele Goldberg sobre a estrutura argumental das Construções Ditransitivas em Inglês. A proposta de Goldberg procurava dar conta das variações de valência verbal sem a necessidade de se postularem regras lexicais que agiriam sobre a estrutura sintática; e deu origem ao que hoje se conhece por Gramática Cognitivista das Construções (GOLDBERG, 2006). 
SALOMÃO, TORRENTI e SAMPAIO - A linguística cognitiva encontra a linguística...

O projeto Frames e Construções propõe um diálogo entre as duas últimas correntes citadas. Estas, embora apresentem mais pontos em comum do que distinções, guardam algumas diferenças que devem ser apontadas (cf. FILLMORE; KAY, 1999; GOLDBERG, 2006). A mais proeminente delas reside no fato de que, enquanto Fillmore reconhece construções puramente sintáticas, Goldberg propõe que toda construção tenha uma contraparte semântica. Em outras palavras, na proposta de Goldberg $(1995 ; 2006 ; 2010)$, toda construção aponta para um significado ou função; já Fillmore assume que existem tipos diferentes de construção: desde aquelas que portam frames e, portanto, significado, até aquelas que são apenas padrões de licenciamento de usos sintáticos (FILLMORE; KAY, 1999; FILLMORE, LEE-GOLDMAN; RHODES, no prelo).

Como as construções que começaram a ser investigadas pelos pesquisadores envolvidos no projeto são todas portadoras de frames, os trabalhos desenvolvidos no âmbito do Frames e Construções partem das bases estabelecidas pela versão Goldbergiana da Gramática das Construções. A ideia é que se possa, mais adiante, propor um diálogo entre essa perspectiva e a de Fillmore.

No momento, o projeto trabalha com duas famílias de construções do PB. A primeira delas, que está na origem da proposta de implementação de um Constructicon para o Português, é a família de Construções em Para Infinitivo (LAGE, 2011; LAGE \& TORRENT, 2012; TORRENT, 2005; 2007; 2008; 2009a; 2009b; 2009c; 2011); e a segunda família de construções estudada é a das Construções de Quantificação Indefinida com Determinantes Polilexêmicos (BRODBECK, 2010).

No que diz respeito às Construções em para infinitivo, Torrent $(2005 ; 2007$; 2008; 2009a; 2009b; 2009c), em trabalhos anteriores, propõe a existência, no PB, de uma rede de construções motivada formal e funcionalmente pela Construção Adjuntiva Final em Para Infinitivo (CAFPI), a qual vem exemplificada em (5):

(5) Ele pagou uma parcela só recorrente ao mês de abril e utilizou o fundo de garantia por tempo de serviço pra quitar todo o saldo devedor. (PROCON $-\mathrm{CEF})$

Tal construção codifica uma meta da ação expressa na construção anterior, à qual serve de adjunto. Essa propriedade semântica da CAFPI foi identificada em outros trabalhos de orientação funcionalista acerca das cláusulas de finalidade infinitivas no PB (DIAS, 2001; 2002; MARTELOTTA, 2001). Dias (2001, p. 163), baseando-se na Teoria da Metáfora, conforme proposta por Lakoff e Johnson (2002 [1980]) e Lakoff (1987), define as cláusulas de finalidade como aquelas que

codificam o movimento no mundo das intenções. O sujeito e/ou locutor estabelecem um propósito ou finalidade, cuja execução do objetivo demanda o deslocamento de uma origem a uma meta, com uma trajetória, no mundo das intenções. Este movimento no mundo das intenções pode sobrepor-se ao deslocamento no mundo físico. 
Cadernos de EsTUDOS LINGǘlsticos (55.1) - Jan./Jun. 2013

Conforme se pode observar no exemplo, a definição de Dias (2001) se aplica à construção ora discutida. Em (1), tem-se que a utilização do FGTS teve como meta a quitação do saldo devedor. Trata-se de um movimento, no mundo das intenções, em que o sujeito que utiliza o fundo visa a atingir, metaforicamente, um destino em que não há mais dívidas a serem quitadas.

Essa descrição semântica coincide com a definição do frame PURPOSE, encontrada no site da FN (http://framenet.icsi.berkeley.edu), segundo a qual a noção de finalidade equivale a uma cena na qual

Um Agente quer atingir um Alvo, ou um objeto, um Meio, foi criado ou é utilizado de modo a permitir a seu criador ou a um usuário atingir esse Alvo. OAlvo é o estado de coisas que não se verifica atualmente, mas que o Agente quer atingir e planeja fazê-lo.

Seguindo o Princípio da Motivação Maximizada, propõe-se que um conjunto de onze construções - de estrutura argumental e idiomáticas -, todas herdeiras do esquema sintático e da contraparte semântica da CAFPI, formam um rede no PB. A configuração de tal rede está representada na Figura 3.

$\mathrm{Na}$ rede, cada construção aparece representada por um retângulo no qual aparecem: (i) na primeira linha, em negrito, o nome da Construção (Cx.); (ii) na segunda, entre colchetes, seu esquema sintático; e (iii) a partir da terceira, sua contraparte semântica. As setas indicam as relações hierárquicas entre as construções, também chamadas, na literatura pertinente, relações de herança construcional. Essas relações apresentam uma tipologia definida por Goldberg (1995), a qual foi amplamente discutida por Torrent em trabalhos anteriores (TORRENT, 2007; 2009a; 2009c; 2011).

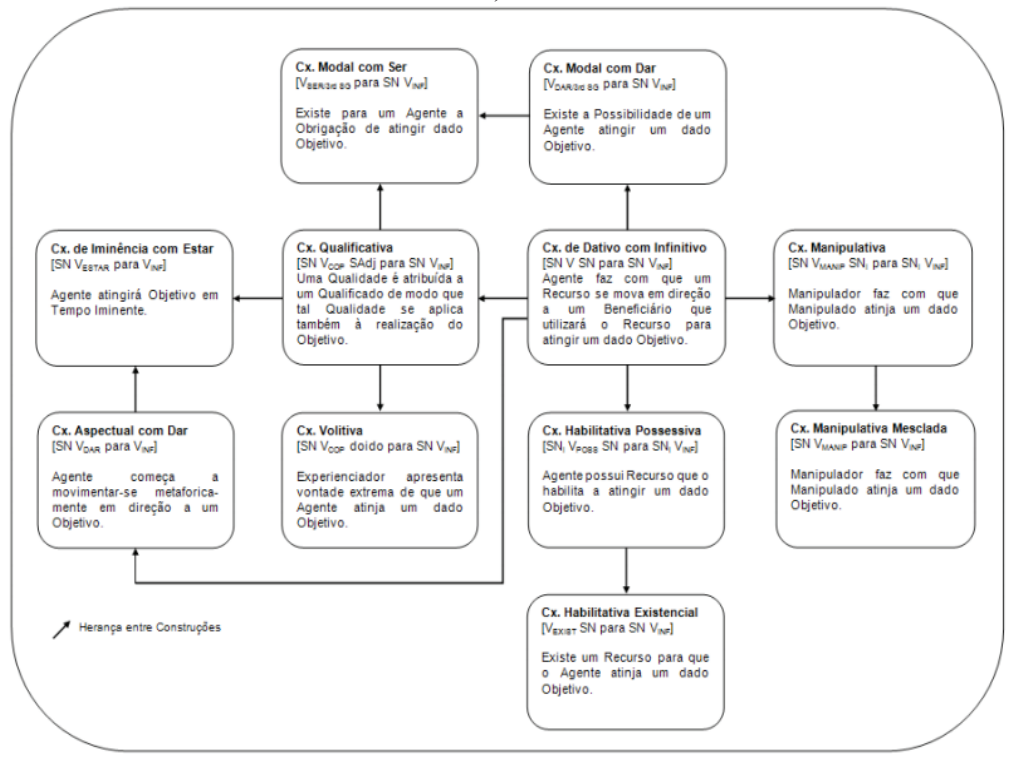

Figura 3. Rede de Construções em Para Infinitivo 
SALOMÃO, TORRENTI e SAMPAIO - A linguística cognitiva encontra a linguística...

Note-se, nesta representação, que todas as construções compartilham o esquema sintático para (SN) infinitivo e, como era de se esperar, têm suas contrapartes semânticas relacionadas ao frame de FINALIDADE (PURPOSE). Entretanto, diferentemente do proposto por Goldberg (2010), as alterações nos "frames" evocados por cada construção - se todos eles poderão ser chamados de frames é algo que ainda será investigado no decorrer do projeto - não podem ser atribuídas exclusivamente aos esquemas de significado dos verbos - ou mesmo dos adjetivos doido e louco, no caso da Cx. Volitiva - que preenchem os slots de estrutura argumental da construção: não é plausível dizer que a UL dar evoca, independentemente da construção em que figura, as noções de incepção e possibilidade. Isso só é possível caso se considere uma intrincada rede de metáforas que se instanciam, justamente, através de construções muito especificadas (vide também, a esse respeito, SALOMÃO, 1990).

De modo análogo, o adjetivo doido, mesmo em contextos sintáticos quase idênticos, não evoca o frame de DESEJO. Tome-se, por exemplo, a sentença "Ele é doido de fazer isso", em que a troca de para por de faz com que o frame evocado seja mesmo o de LOUCURA.

A partir desses dois exemplos, fica clara a relevância de se investigar de que modo ULs e construções se combinam para evocar frames e a família de construções em para infinitivo, assim como a família de frames relacionados à FINALIDADE serve muito bem a esse propósito, uma vez que, nessa família, encontra-se toda miríade de construções possíveis - das altamente especificadas às altamente abertas -, o que ajudará a entender melhor a relação entre frames e construções. Ademais, através do estudo dessas construções, será possível mesmo verificar a validade dos outputs gerados pela FrameNet como ferramentas de descrição linguística que extrapolem os limites da lexicografia. Isso porque, nessa família (cf. LAGE, 2011; LAGE \& TORRENT, 2012), há tanto construções de estrutura argumental tratáveis como padrões de valência das ULs verbais que figuram no slot do V finito, quanto padrões construcionais bastante abertos no que tange aos itens lexicais que podem preenchê-los, sendo, porém, muito especificados sintaticamente.

A segunda família de construções estudada por pesquisadores do projeto Frames e Construções é a das Construções de Quantificação Indefinida com Determinantes Polilexêmicos. Tais Construções começaram a ser investigadas no trabalho de Brodbeck (2010), que analisou o processo de gramaticalização dos sintagmas monte de $\mathrm{N}$ (monte de problemas) e chuva de $\mathrm{N}$ (chuva de críticas), que se consolidam como determinantes polilexêmicos, no interior da Construção de Quantificação Nominal em Português. Contudo, como a própria autora faz questão de frisar, tal estudo é apenas o passo inicial numa investigação muito mais complexa e abrangente, que deverá dar conta do amplo conjunto de determinantes polilexêmicos usados na Construção de Quantificação Nominal no PB. Alguns desses determinantes vão ilustrados nas sentenças de (6) a (9).

(6) No caso, Maradona ostentava um oceano de razões.

(7) Um verdadeiro dilúvio, uma enchente de cartas inunda a redação. 
Cadernos de ESTUDOS LINGǘlsticos (55.1) - Jan./Jun. 2013

(8) Se ganhar o título vai receber um caminhão de pontos no ranking.

(9) Fiquei nadando em um mar de dúvidas.

De fato, uma análise mais completa da Construção precisará incluir tanto os determinantes de grande quantidade (1), como os de pequena quantidade (2):

\begin{tabular}{|c|c|}
\hline \multicolumn{2}{|c|}{ (1) Determinantes Polilexêmicos de Grande Quantidade } \\
\hline um caminhão de & $\begin{array}{l}\text { Santos perde um caminhão de gols, mas bate Vitória e } \\
\text { fica em vantagem. }\end{array}$ \\
\hline uma montanha de & Eles têm uma montanha de dinheiro para reagir. \\
\hline um mar de & $\begin{array}{l}\text { Psiquiatra Bili Marques derrama um mar de mentiras } \\
\text { em rádio local. }\end{array}$ \\
\hline uma floresta de & O comício era uma floresta de gente e de bandeiras. \\
\hline uma enchente de & $\begin{array}{l}\text { O novo centro comercial de Portimão abriu com } \boldsymbol{u m a} \\
\text { enchente de clientes. }\end{array}$ \\
\hline um mundo de & Brasil e China: um mundo de oportunidades. \\
\hline uma galáxia de & Você é uma galáxia de informação. \\
\hline um oceano de & Algas marinhas: um oceano de benefícios. \\
\hline um vendaval de & $\begin{array}{l}\text { Tropa de elite" estréia nos EUA em meio a um vendaval } \\
\text { de críticas. }\end{array}$ \\
\hline um iceberg de & $\begin{array}{l}\text { Globopar é a ponta de um iceberg de passivos privados } \\
\text { em dólar. }\end{array}$ \\
\hline uma jamanta de & $\begin{array}{l}\text { essa dádiva divina tem de vir acompanhada de uma } \\
\text { jamanta de triglicerídeos }\end{array}$ \\
\hline uma enxurrada de & Uma enxurrada de Historias pra você. \\
\hline \multicolumn{2}{|c|}{ (2) Determinantes Polilexêmicos de Pequena Quantidade } \\
\hline um grão de & $\begin{array}{l}\text { Nada conseguiriu dos meus olhos arrancar um grão de } \\
\text { vontade }\end{array}$ \\
\hline um pingo de & $\begin{array}{l}\text { Aliás, se tivesse um pingo de vergonha na cara, } \\
\text { deveria pedir demissão. }\end{array}$ \\
\hline uma gota de & Talvez, uma gota de esperança há de existir. \\
\hline um dedinho de & Não tinha um dedinho de consideração por nós. \\
\hline um caco de & $\begin{array}{l}\text { mas ainda me resta "um caco" de esperança de que } \\
\text { um dia mudará. }\end{array}$ \\
\hline um cisco de & $\begin{array}{l}\text { Boa tarde pra você que está sem um cisco de vontade } \\
\text { de assistir aula! }\end{array}$ \\
\hline um fio de & $\begin{array}{l}\text { elfos e não têm um fio de bondade em seus corpos } \\
\text { encaroçados }\end{array}$ \\
\hline
\end{tabular}


SALOMÃO, TORRENTI e SAMPAIO - A linguística cognitiva encontra a linguística...

A princípio, salta aos olhos a filiação de grupos de nomes que preenchem a posição $\mathrm{X}$ em [um(a) X de N] a campos semânticos específicos: grandes contêineres (caminhão, galáxia, jamanta); fenômenos da natureza de grande intensidade (chuva, vendaval, enxurrada); fragmentos e pequenas partes de um todo (grão, caco, pingo, gota). Por outro lado, faz-se necessário investigar também por que alguns nomes pertencentes a campos semânticos próximos não seriam admitidos na construção. Tome-se, por exemplo, a impossibilidade de se encontrar "uma garoa de problemas" ou "um floco de dúvida".

De todo modo, percebe-se que as Construções de Quantificação Indefinida com Determinantes Polilexêmicos, assim como ocorre com a construção [SN $\mathrm{V}_{\text {SER/ESTAR }}$ doido para $\mathrm{V}_{\text {INF }}$, são especificadas quanto ao preenchimento lexical de suas posições sintáticas. Assim, torna-se relevante fazer um levantamento dos determinantes polilexêmicos usados na Construção de Quantificação Nominal do $\mathrm{PB}$, atestando o uso desses determinantes em grandes corpora. Até o momento, tendo focado apenas nos determinantes de grande quantidade, a pesquisa já reuniu mais de quinhentas instanciações da construção no corpus utilizado pela FN-Br, tendo atestado o uso de pelo menos dez determinantes polilexêmicos de grande quantidade: uma enxurrada de ações; uma porrada de gente, um mar de miséria, uma floresta de cadeiras, um oceano de sangue, um montão de bonecas, uma montanha de papel, um vendaval de amofinações, uma galáxia de coisas, uma enchente de jornalistas.

Assim, a proposta de implementação do Constructicon do Português do Brasil - produto tecnológico do projeto Frames e Construções -, representa contribuições significativas em duas frentes igualmente relevantes para o desenvolvimento da pesquisa linguística no Brasil. Do ponto de vista da Linguística Teórica, o projeto oferece, nesta fase inicial, um estudo detalhado de duas famílias de construções do PB, com a descrição de aspectos sintáticos, semânticos e pragmáticos das Construções investigadas e de suas partes, nos termos de Fillmore, Goldman e Rhodes (no prelo). Já da perspectiva da Linguística Computacional, o projeto configura um importante avanço na busca por mecanismos de reconhecimento automático e interpretação algorítmica de construtos lexicalmente especificados.

\section{REFERÊNCIAS BIBLIOGRÁFICAS}

ATKINS, Sue; RUNDELL, Michael and SATO, Hiroaki. (2003). The Contribution of Framenet to Practical Lexicography, International Journal of Lexicography, Volume 16.3, p.333-357.

ATKINS, Sue, FILLMORE, Charles J. and JOHNSON, Christopher R. (2003). Lexicographic Relevance: Selecting Information From Corpus Evidence, International Journal of Lexicography, Volume 16.3, p. 251-280.

BAKER, Collin F., Charles J. FILLMORE and CRONIN, Beau. (2003). The Structure of the Framenet Database, International Journal of Lexicography, Volume 16.3: 281-296.

BAKER, Collin F., FILlMORE, Charles J., and LOWE, John B. (1998). The Berkeley FrameNet project. In Proceedings of the COLING-ACL, Montreal, Canada. 
BAKER, Collin F. and RUPPENHOFER, Josef. (2002). FrameNet's Frames vs. Levin's Verb Classes. In J. Larson and M. Paster (Eds.) In Proceedings of the 28th Annual Meeting of the Berkeley Linguistics Society. 27-38.

BAKER, Collin F. and SATO, Hiroaki. (2003). The FrameNet Data and Software. Poster and Demonstration at Association for Computational Linguistics, Sapporo, Japan.

BERNES-LEE, T. HENDLER, J.; LASSILA, O. (2010). The Semantic Web. A new form of Web content that is meaningful to computers will unleash a revolution of new possibilities. Scientific American, 01/05/2001. Disponível em: http://www.scientificamerican.com/ 2001/0501 issue/0501bernerslee. Acesso em: 5 nov de 2010.

BOAS, Hans C. (2001). Frame Semantics as a framework for describing polysemy and syntactic structures of English and German motion verbs in contrastive computational lexicography. In: Rayson, Paul, Andrew Wilson, Tony McEnery, Andrew Hardie, and Shereen Khoja (Eds.), Proceedings of the Corpus Linguistics 2001 conference. Technical Papers, Vol. 13. Lancaster, UK: University Centre for computer corpus research on language.

(2002). Bilingual FrameNet Dictionaries for Machine Translation. In M. Gonzalez Rodríguez and C. Paz Suarez Araujo (eds.), Proceedings of the Third International Conference on Language Resources and Evaluation. Las Palmas, Spain. Vol. IV: 1364-1371.

. (2005). "Semantic Frames as Interlingual Representations for Multilingual Lexical Databases" In: International Journal of Lexicography 18(4), p. 445-478.

BRODBECK, R. C. M. S. (2010). Um monte de problemas gera uma chuva de respostas: um estudo de caso de desencontro na quantificação nominal em português. Tese (Doutorado em Linguística) - Faculdade de Letras, Universidade Federal de Juiz de Fora.

CHISHMAN, R. L. O. (2009a). Integrando Léxicos Semânticos e Ontologias: uma aproximação a favor da web semântica. Informação \& Informação, Londrina: UEL, v. 14, n. esp., p. 103 - 124. . (2009b). FrameCorp: uma proposta de anotação semântica aplicada à temática do futebol. Projeto de Pesquisa apresentado ao CNPq.

COULSON, Seana (Accepted, 2009). Cognitive Neuroscience of Figurative Language. In M.J. Spivey, M. Joanisse, \& K. McCrae \& (Eds.). The Cambridge Handbook of Psycholinguistics. Cambridge: Cambridge University Press.

DIAS, N. B. (2001). As Cláusulas de Finalidade. 2001. 175 f. Tese de Doutorado em Linguística, Universidade Estadual de Campinas, Campinas.

. (2002). As Funções Discursivas das Cláusulas de Finalidade. Veredas, Juiz de Fora: UFJF, v.6, n.2, p. 137-148, jul./dez.

FELDMAN, J. (2006). From molecule to metaphor: a neural theory of language. Cambridge, Mass.: MIT Press.

FELLBAUM, Christiane (1990). English verbs as a semantic net in International Journal of Lexicography, 3(4), p. 278-301.

. (1998). Semantic Network of English Verbs, In: Fellbaum, Christiane (Ed.), WordNet: an electronic lexical database .The MIT Press, Cambridge, Massachusetts, p. 69-104.

FILLMORE, Charles J. Scenes-and-frames semantics, Linguistic Structures Processing. (1977a). In: Zampolli, Antonio (Ed.): Fundamental Studies in Computer Science, No. 59, North Holland Publishing, p. 55-88.

(1977b). The need for a frame semantics in linguistics, In Karlgren, Hans (Ed.): Statistical Methods in Linguistics 12: 5-29.

. (1982). Frame semantics. In Linguistics in the Morning Calm, Seoul, Hanshin Publishing Co., 111-137. 
SALOMÃO, TORRENTI e SAMPAIO - A linguística cognitiva encontra a linguística...

(1985). Frames and the semantics of understanding. In Quaderni di Semantica, Vol. 6.2: 222254.

(2008). Border Conflicts: FrameNet Meets Construction Grammar. In: EURALEX,13, 2008, Barcelona. Anais. Barcelona: Universitat Barcelona Fabra.

(1992). "Corpus linguistics" vs. "computer-aided armchair linguistics", In Directions in Corpus Linguistics: Proceedings from a 1991 Nobel Symposium on Corpus Linguistics. Stockholm: Mouton de Gruyter, 35-66.

FILLMORE, C.J., KAY, P. and O'CONNOR, M. C. (1988). Regularity and idiomaticity in grammatical constructions. Language, 64(3): 501-538.

FILLMORE, Charles J. and B. T. S. ATKINS. (1992). Towards a frame-based lexicon: The semantics of RISK and its neighbors. In Lehrer, A and E. Kittay (Eds.) Frames, Fields, and Contrast: New Essays in Semantics and Lexical Organization. Hillsdale: Lawrence Erlbaum Associates, 75-102.

FILLMORE, Charles J. and B. T. S. ATKINS. (1994). Starting where the dictionaries stop: The challenge for computational lexicography, In Atkins, B. T. S. and A. Zampolli (Eds.) Computational Approaches to the Lexicon. Oxford: Oxford University Press, 349-393.

FILLMORE, C. J, LEE-GOLDMAN, R. \& RHODES, R. The FrameNet Constructicon. In: BOAS, H. \& SAG, and I. Sign-Based Construction Grammar. No prelo.

GAMONAL, Maucha A. Copa 2014 FrameNet Brasil: Análise da Unidade Lexical "Visitar" do Frame de Turismo. Anais do SILEL, v.2, n.2. Uberlandia: EDUFU, 2011.

GAMONAL, Maucha A. \& TORRENT, Tiago T. (2012). 2014 World Cup FrameNet Brazil: Building a frame-semantics-based electronic trilingual dictionary for the domains of Tourism and Football. $4^{\text {th }}$ United Kingdom Cognitive Linguistics Conference. (Comunicação oral).

GUARINO, Nicola \& WELTY, Chris. (2002). An Overview of OntoClean. In Steffen Staab and Rudi Studer, eds., The Handbook on Ontologies. Pp. 151-172. Berlin: Springer-Verlag, 2004. HAUSER, M. D., CHOMSKY, N., and FITCH, W. T. The Faculty of Language: What Is It, Who Has It, and How Did It Evolve? Science, 298:1569-1579.

LAGE, Ludmila M. (2011). Frames e Construções: Um Estudo de Caso da Construção [SN V deixar Para/ Por $\mathrm{V}_{\text {infinitivo }}$ ] e do Frame de Deixado_por_fazer. Anais do SILEL, v.2, n.2. Uberlândia: EDUFU.

LAGE, Ludmila M. \& TORRENT, Tiago T. (2012). Frames and Constructions: Building the Brazilian Portuguese Constructicon. $4^{\text {th }}$ United Kingdom Cognitive Linguistics Conference. (Comunicação oral).

LAKOFF, G. (1987). Women, Fire and Dangerous Things: What categories reveal about the mind. Chicago: University of Chicago Press.

LAKOFF, G. \& JOHNSON, M. (2002)). Metáforas da Vida Cotidiana. Trad. Vera Maluf. Campinas: Mercado de Letras. (original de 1980)

LINDE-USIEKNIEWICZ J., OLKO M. (2006). Multilingual dictionaries on-line: reality and perspectives in: Semantyka a konfrontacja językowa, t. 3 (ed. Violeta Koseska, Roman Roszko), str. 11-32, SOW.

MACHADO, Patrícia M. (2011). A Construção Superlativa Sintética de Estados Absolutos com o sufixo-íssimo: um caso de Desencontro/ Mismatch morfológico. Dissertação de Mestrado apresentada ao Programa de Pós Graduação em Linguística da Universidade Federal de Juiz de Fora 
MARTELOTTA, M. E. (2001). Vinculação em Cláusulas Adverbiais: Uma análise de cláusulas finais. In: DECAT, Maria Beatriz, BITTENCOURT, Vanda de Oliveira e BRAGA, Maria Luiza (Org.). Scripta: Revista do Programa de Pós-Graduação em Letras e do CESPUC. Belo Horizonte: PUC-MG, v. 5. p. 54-66.

MATOS, Ely Edison ; CAMPOS, F. C. A. ; BRAGA, Regina ; PALAZZI, Daniele . (2009). CelOWS: an ontology based framework for the provision of semantic web services related to biological models. Journal of Biomedical Informatics, v. 43, p. 125-136.

MENDES, L. F. ; SILVA, L. ; MATOS, E. ; BRAGA, R. M. M. ; CAMPOS, F. C. A. (2011). SASAgent: an Agent Based Architecture for Search, Retrieval and Composition of Scientific Models. Journal of Computers in Biology and Medicine, v. 1, p. 1-14.

MINSKY, M. (1975). A framework for representing knowledge. In: WINSTON, P. (Org.). The psychology of computer vision. New York: Mc Graw-Hill. Disponível em: http://web.media. mit.edu/ minsky/papers/Frames/frames.html Acesso em 30 out. 2010.

PIATTELli-PAlMARINI, M., SAlABURU, P., and URIAGEREKA, J. (2009). Of Minds and Language: A Dialogue with Noam Chomsky in the Basque Country. Oxford University Press.

PINKER, S., \& JACKENDOFF, R. (2005). The faculty of language: What's special about it? Cognition 95, 201-236.

PRÉVOT, Laurent; Stefano BORGO; Alessandro OLTRAMARI. (2005). Interfacing ontologies and lexical resources. In Proceedings of OntoLex 2005: Ontologies and Lexical Resources. Asian Federation of Natural Language Processing. Jeju Island, Korea.

RUPPENHOFER, J.; ELLSWORTH, M.; PETRUCK, M.; JOHNSON, C.; SCHEFFCZYK, J. (2010). FrameNet II: Extended Theory and Practice. Versão 14 set. 2010. Disponível em: http:// framenet.icsi.berkeley.edu/Acesso em 20 out. 2010.

SALOMÃO, M. M. M. (1990). Polysemy, aspect and modality in Brazilian Portuguese: the case for a cognitive explanation of grammar. 295 f. Tese de Ph.D. em Linguística, University of California at Berkeley, Berkeley.

. (2002). Gramática das construções: a questão da integração entre sintaxe e léxico. Veredas, Juiz de Fora: UFJF, v.6, n.1, p. 63-74, jan./jun.

(2009). FrameNet Brasil: um trabalho em progresso. Calidoscópio, São Leopoldo: UNISINOS, vol. 7 n. 3, p. 171-182, set/dez.

SANTOS, N.; CAMPOS, F. C. A.; BRAGA, R. M. M. (2008). Digital Libraries and Ontology. In: Yin Leng Theng; Schubert Foo; Dion Hoe-Lian Goh; Jin-Cheon Na. (Org.). Handbook of Research on Digital Libraries: Design, Development, and Impact. Hershey, Pennsylvania: Idea Group Inc, v. 1.

SCHMIDT, T. (2006). Interfacing Lexical and Ontological Information in a Multilingual Soccer FrameNet. In: Proceedings of OntoLex 2006 - Interfacing Ontologies and Lexical Resources for Semantic Web Technologies. Gênova, mai. . (2007). The Kicktionary: A Multilingual Resource of the Language of Football. In: REHM, G., WITT, A. \& LEMNITZER, L. (eds.). Data Structures for Linguistic Resources and Applications. Tübingen: Gunter Narr.

TALMY, Leonard. (2000). Toward a cognitive semantics. Cambridge, Mass.: MIT Press.

TOMASELlO, M. (1999). The Cultural Origins of Human Cognition. Harvard University Press. (2000). Primate cognition: Introduction to the issue. Special Issue (M. Tomasello, Ed.), Cognitive Science, 24, 351-362. 
SALOMÃO, TORRENTI e SAMPAIO - A linguística cognitiva encontra a linguística... (2003). Constructing a Language: A Usage-Based Theory of Language Acquisition. Harvard University Press. . (2008). Origins of Human Communication. MIT Press.

TORRENT, T. T. (2005). O Homem Vai Botar Uma Casa Para Mim Morar - Uma abordagem sociocognitivista e diacrônica da Construção de Dativo com Infinitivo. 2005. 77 f. Dissertação de Mestrado em Letras - Linguística. Universidade Federal de Juiz de Fora, Juiz de Fora. . (2007). A Gramaticalização das Construções Modalizadoras Herdeiras do Dativo com Infinitivo: evidências em favor da necessidade de empreender análises históricas nos estudos orientados pela perspectiva da Gramaticalização. Domínios de Linguagem, v. 1, p. 1-22. . (2008). A construção de dativo com infinitivo: Uma abordagem sociocognitivista e diacrônica. Veredas On Line, v. 1, p. 95-111.

. (2009a). A Hipótese da Dupla Origem para A Construção de Dativo com Infinitivo: primeiras incursões pelo Português Medieval. Revista da ABRALIN, v. 7, p. 65-92. Belo Horizonte: ABRALIN.

. (2009b). A Construção de Dativo com Infinitivo. In: MIRANDA, Neusa Salim \& SALOMÃO, Maria Margarida Martins (Org.). Construções do Português do Brasil. Belo Horizonte: UFMG.

(2009c). A Rede de Construções em Para (SN) Infinitivo: uma abordagem centrada no uso para as relações de herança e mudança construcionais. 166 f. Tese de Doutorado em Linguística. Universidade Federal do Rio de Janeiro, Rio de Janeiro.

. (2011). Frames e Construções: o repertório sintático-semântico da finalidade e noções adjacentes no Português do Brasil. Projeto de Pesquisa - FAPEMIG. Juiz de Fora: UFJF, mar. 